\title{
Avrupa ve Orta Asya Bağlamında Türkiye'de Kamu Özel Ortaklığı
}

\author{
DOI: $10.26466 /$ opus.734382
}

\section{Semra Altıngöz Zarpli *}

* Dr. Öğr. Üyesi, Bilecik Şeyh Edebali Üniversitesi/İ̈BF, Bilecik/Türkiye E-Posta: semra.altingoz@bilecik.edu.tr

ORCID: $\underline{0000-0003-4597-0193}$

\section{Öz}

Kamu özel ortaklığı, ülkelerin hızlı nüfus artışları ve bu nüfusun kaliteli hizmet beklentisi içine girmesiyle kamu sektörü ve özel sektörün çeşitli yatırımlarla ilgili birtakım riskleri paylaştı̆̆ı bir model olarak tanımlanmaktadır. Kamu Özel Ortaklığı modeli ile özel sermayeli altyapı projelerinin geliştirilmesi, gelişmiş ve gelişmekte olan ülkelerde yaygın olarak benimsenen satın alma stratejilerinden biri haline gelmiştir. Model hemen hemen tüm ülkelerde farklı şekillerde uygulanmaktadır. Bu sebeple de kamu özel ortaklığı modelinin tek bir tanımını yapmak mümkün olmamaktadır. Tek bir tanım yapmanın olanaklı olmadığı bu modelde aynı zamanda Avrupa ve Orta Asya ülkelerinde kamu ortaklı̆̆l modelinde bölgelere göre sektörel yatırım projelerinde de ülke önceliklerine gore farklılıklar gözlenmiştir. Sektörel yatırım projelerinde elektrik projelerinin, havaalanları projelerinin ve yol projelerinin toplam proje yatırımları içerisinde ilk sıralarda yer aldığg görülmüştür. Türkiye'de gerçekleştirilen proje sayıları ve yatırım miktarı itibariyle de elektrik sektörü projeleri ilk sırada yer almaktadır. Havaalanı projelerini, doğal gaz ve liman projeleri takip etmiştir. Ayrıca Türkiye'nin gelişmekte olan ülkeler arasında kamu özel ortaklığ projelerini uygulama konusunda iyi örnekler arasında yer aldığı görülmüştür.

Anahtar Kelimeler: $\quad$ Kamu-Özel Ortaklığı, Avrupa ve Orta Asya, Sektörel Yatırım Projeleri 


\title{
Public Private Partnership in Turkey within the Context of European and Central Asian
}

\begin{abstract}
Public-private partnership can be defined as a method which public sector and private sector share risks related to required investments. Public-private partnerships are defined as a method of contract for developing and maintaining infrastructure services, utilizing innovation and skills of private sector in order to manage operations which use private financing. Nevertheless, there is no universally accepted definition of its. It can be uttered with several different concepts depending upon its implementation means in each country. Local governments in developing countries confront with major challenges such as providing and sustaining fundamental services to their own citizens, and financing infrastructure, implementing and sustaining it to support economic growth. Local governments endeavor to produce a number of goods and services with limited sources of income. Local governments are considered as the political equivalent of the free market; and certain duties and services being undertaken by local governments are formed within this framework. Recently it has been deemed that the decentralized structure is rapidly dominating in the world, and as one of the elements for improving local service quality the public-private partnership method has already started to be used.
\end{abstract}

Keywords: Public-Private Partnership, Europe and Central Asia, Investment in Sector 


\section{Giriş}

Özel sektörün ve kamu sektörünün gönüllü birleşimini ortaklık olarak nitelendiren kamu özel ortaklığı modelinin farklı tanımları mevcuttur. Kamu özel ortaklığı, özel sektörün altyapı tedarikine katıldığı veya destek sağladığ 1 başka bir ifadeyle kamu altyapısına dayalı hizmetleri sunma amaçlı özel bir kuruluşun sözleşmesine imkan tanıyan düzenlemeler olarak da tanımlanabilmektedir (Grimsey ve Lewis; 2014, s.2).

OECD'nin yapmış olduğu kamu özel ortaklığı modelinin tanımı, özel sektörle devlet kurumu arasında, özel sektörün önemli bir risk ve yönetim sorumluluğu üstlendiği ve ücretlendirmenin performansla bağlantılı olduğu bir kamu mal veya hizmeti sağlamak için yapılan uzun vadeli bir sözleşmedir (https://pppknowledgelab.org/guide/sections/1-introduction).

Kamu-özel ortaklığının tanımında ortak bir uzlaşıya varılamadığı fakat iki büyük kategoride ele alındığı görülmektedir. İlk kategori kamu-özel ortakl1ğını geniş anlamda tanımlamaktadır. Buna göre ilk kategori kamu-özel ortaklığını, çeşitli kamu özel işbirliği formlarını kapsayacak şekilde geniş anlamda ele almaktadır. Bu kategoriye göre kamu özel ortaklığı kamunun müdahalesini, kamu hizmeti veya alt yapı çalışmasını gerçekleştirme olarak ifade etmiştir. İkinci kategoriye göre ise kamu-özel ortaklığı birtakım vazgeçilmez özellikleri bünyesinde barındırmaktadır. Bu özellikler riskler, ortaklar, bir kamu ve bir özel ortaklar arasında paylaşım, maliyetler, faydalar, kaynaklar ve sorumluluklardır. Bu çerçevede, ikinci kategori kamu-özel ortaklığını tanımlamaya daha yakın görülmektedir. Ne var ki, uluslararası uygulamada, kamu-özel ortaklığı, çeşitli alanlar, devletlerin özellikleri ve bunun için kullanılan farklı ihtiyaçlar nedeniyle çeşitli biçimlerde ortaya çıkmaktadır (Zaharioare, 2012, s.18).

Bütün bu tanımlamalardan kamu özel ortaklığı modeli ile ilgili birtakım ifadelerin yanlış anlamlandırıldığı görülmektedir. Kamu özel ortaklığı modeli bir özelleştirme olarak anlamlandırılmamalıdır. Bir kamu projesinde özel sektörün uzun vadeli bir imtiyaz veya finansal kiralama sözleşmesi yoluyla operasyonel bir rol üstlendiği bir süreçtir. Bu ortaklık özelleştirmeden farklı olarak, bir kamu tesisinin mülkiyeti veya unvanının özel bir işletmeye devredilmesidir. Kamu özel ortaklıkları, kamu kurumunun bir altyapı projesinin uzun vadeli bir sözleşmesinin tam olarak sahipliğini elinde tutmasına izin verdiği kamu ve özel sektörler arasındaki bir ilişkidir; işletme tesisi işletmekte 
ve bunun neticesinde elde edilen geliri toplamaktadır. Bazı uzmanlar, kamu özel ortaklığında aslında bir ortaklık olmadığını iddia etmektedirler. Çünkü ticari faaliyetlerin paylaşılmadığını savunmaktadırlar. Ev sahibi ve kiracı arasındakine benzer biçimde yalnızca basit bir ilişki durumu bulunmaktadır. Dünya genelinde ve özellikle ABD'de kaliteli altyapıya olan talep devam ettiğinden kamu fonlarının mevcudiyeti azalmaktadır (Levy, 2011, s.1).

\section{Kamu Özel Ortaklığı Modelinin Avantajlanı ve Dezavantajlanı}

Kamu özel ortaklığı modeli bir takım avantaj ve dezavantajlara sahiptir. İhtiyaç duyulan tesis ve altyapı projelerini yerel yönetimlerin kendi başlarına gerçekleştirecekleri çalışmalardan daha hızlı ve daha ucuza sunabilirler. Yüklenicilere projenin çeşitli riskleri aktarılabilir ve özel sektörün uzmanlığına ve finansmanına erişim sağlanabilir. Böylece kamu kurumları projeler ile ilgili bir takım riskleri özel bir ortağa aktarabilir. Belirli bir proje türü hakkında daha fazla deneyime sahip olan özel yüklenici ortak ile risk paylaşımına izin veren kamu özel ortaklığı modelinde bu risklerden kaynaklı meydana gelebilecek maliyet artışlarını azaltmak için stratejiler de geliştirilebilmektedir (Martin, 2018, s.2).

Kamu özel ortaklığı modeli, bünyesinde bir takım dezavantajları da barındırmaktadır. Model, geleneksel devlet finansmanı yöntemlerine kıyasla daha yüksek maliyetlerle sonuçlanabilmektedir. Sadece sınırlı sayıda teklif veren/tedarikçi bu yöntemle ilgilenebilmektedir. Kamu-özel ortaklığı modeli yerel yönetimlerin karar verme esnekliklerini de azaltmaktadır. Vatandaşlar kamu-özel ortaklığı modelini anlamakta güçlük çekmekte ve projelerin şeffaflık ilkesine uymadıklarını düşünmektedir (Martin, 2018, s.2).

Kamu özel ortaklığ 1 için satınalma süreci, geleneksel olarak devlet altyapı projeleri için (tasarım-teklif-tasarım ve tasarım-inşa gibi) kullanılan tedarik süreçlerinden daha karmaşıktır. Bir projenin tasarımına, inşaat fiyatına ve programına ek olarak, kamu özel ortaklığı yaklaşımı altında, hükümet kuruluşu aynı zamanda finansman, operasyonlar ve bakıma dayalı teklifleri değerlendirmelidir. Kamu özel ortaklığg ihaleleri, hükümetle projeyi teklif eden özel geliştiriciler arasında karmaşık müzakereleri de içerebilir. Örneğin, devlet taslak sözleşmeleri hazırlamak için kötü bir iş yaparsa veya bu sözleşmelerdeki ilgili sorunları çözemezse, beklenmeyen maliyetlerle karşılaşabilir veya planlanandan daha düşük hizmet seviyeleri alabilir (Taylor, 2012, s.12). 
Tablo 1. Kamu Özel Ortakliğının Avantajlarn ve Dezavantajları

\begin{tabular}{ll}
\hline Avantajlar & Dezavantajları \\
\hline $\begin{array}{l}\text { Daha hızlı ve daha ucuz teslimat } \\
\text { tesisler ve altyapı }\end{array}$ & Artan finansman maliyetleri \\
\hline Yüklenicilere proje risk transferi & Karmaşı tedarik ve müteahhitlik \\
\hline Özel sektör uzmanlı̆̆ına erişim & Çok az sayıda teklif veren / sağlayıcı \\
\hline Özel sektör finansmanına erişim & Karar vermede daha az esneklik \\
& Vatandaşlar tarafından iyi anlaşlamama \\
& Şeffaflık eksikliği \\
\hline
\end{tabular}

Kaynak: Martin, 2018, s.3

\section{Avrupa ve Orta Asya'da Kamu Özel Ortaklığı Modeli}

Dünya Bankası'nın Avrupa ve Orta Asya'da kamu özel ortaklığı projelerinin bölgelere göre sektörel dağılımı incelendiğinde, elektrik üretimi projeleri için ayrılan yatırım payları büyük orana sahiptir. Havaalanları projeleri için ayrılan yatırım payları da önemli orana sahiptir.

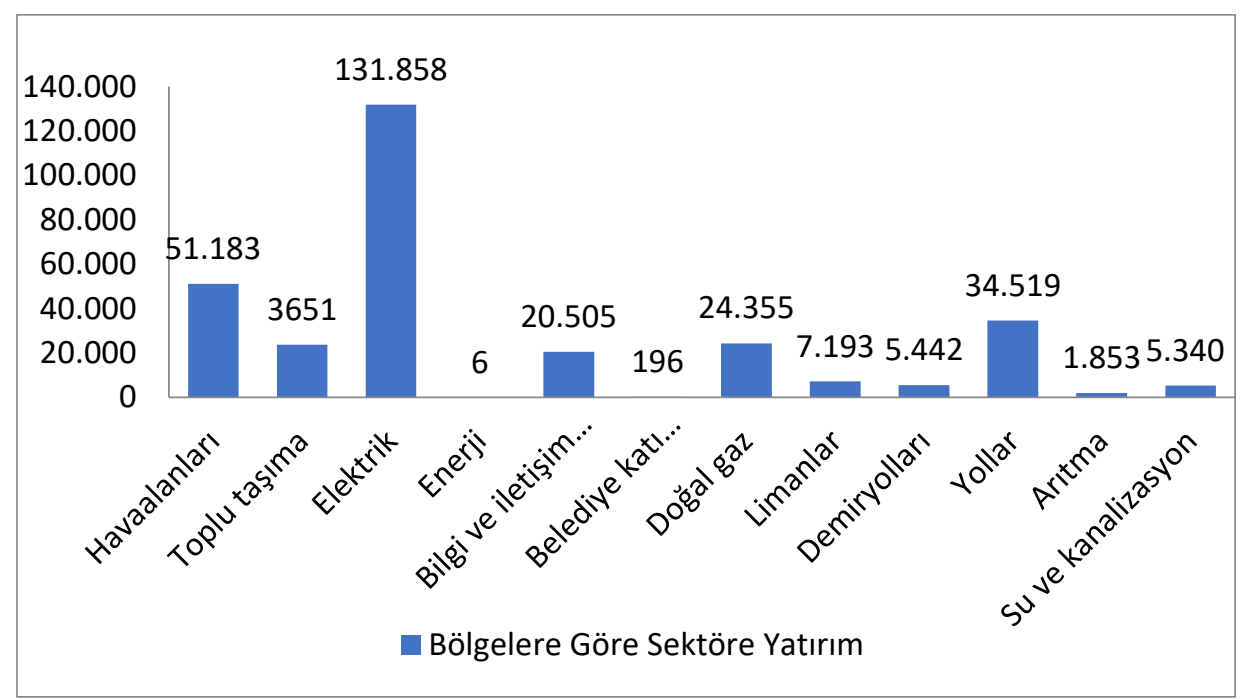

Grafik 1. Bölgelere Göre Sektörel Yatırm (Milyon Dolar) (1990-2019)

Kaynak: The World Bank, 2019

Ortalama proje büyüklükleri açısından elektrik projelerinin 131,858 milyon dolar, havaalanları projelerinin 51,183 milyon dolar, yol projelerinin 34,519 milyon dolar tutarında olduğu görülmektedir. Bu proje yatırımlarını 
takip eden doğalgaz projelerinin 24,355 milyon dolar, bilgi ve iletişim teknolojileri projelerinin de 20,505 milyon dolar olduğu görülmektedir.

Belediye katı atıklarının entegre yönetimi projeleri 196 milyon dolar , limanlar 7,193 milyon dolar, demiryolları projeleri 5,442 milyon dolar, arıtma projeleri 1,853 milyon dolar, su ve kanalizasyon projeleri 5,340 milyon dolar ve toplu taşıma projeleri 3,651 milyon dolardır.

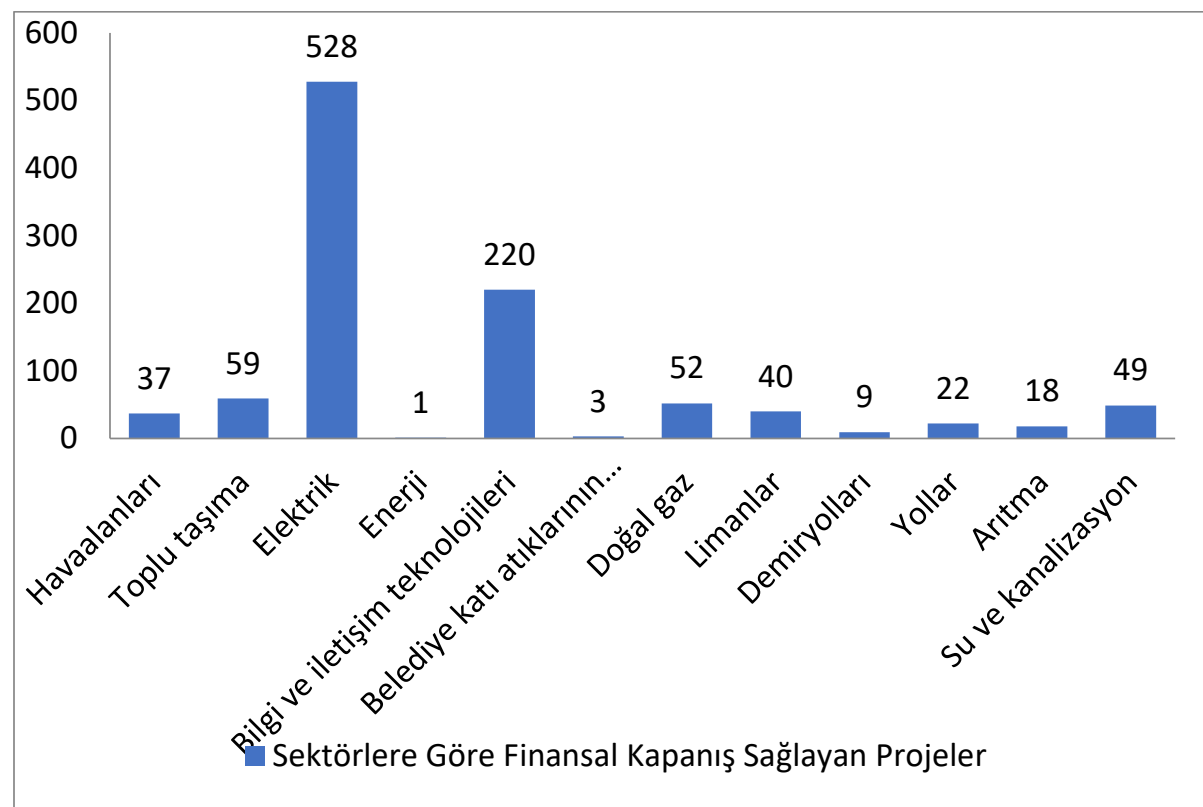

Grafik 2. Sektörlere Göre Finansal Kapanış Sağlayan Projeler (1990-2019)Kaynak:

The World Bank, 2019

1990-2019 yılları arasında sektörlere göre gerçekleştirilen proje sayılarında elektrik sektörü projesi sayısı 528'dir. Bilgi ve iletişim teknolojileri sektörü proje sayısı 220 tanedir. Toplu taşıma sektörü projeleri ile doğal gaz sektörü projeleri sayıları yakın miktarlardadır. Sektörel proje sayıları arasında en düşük paya sahip olan enerji sektörü projeleridir. 


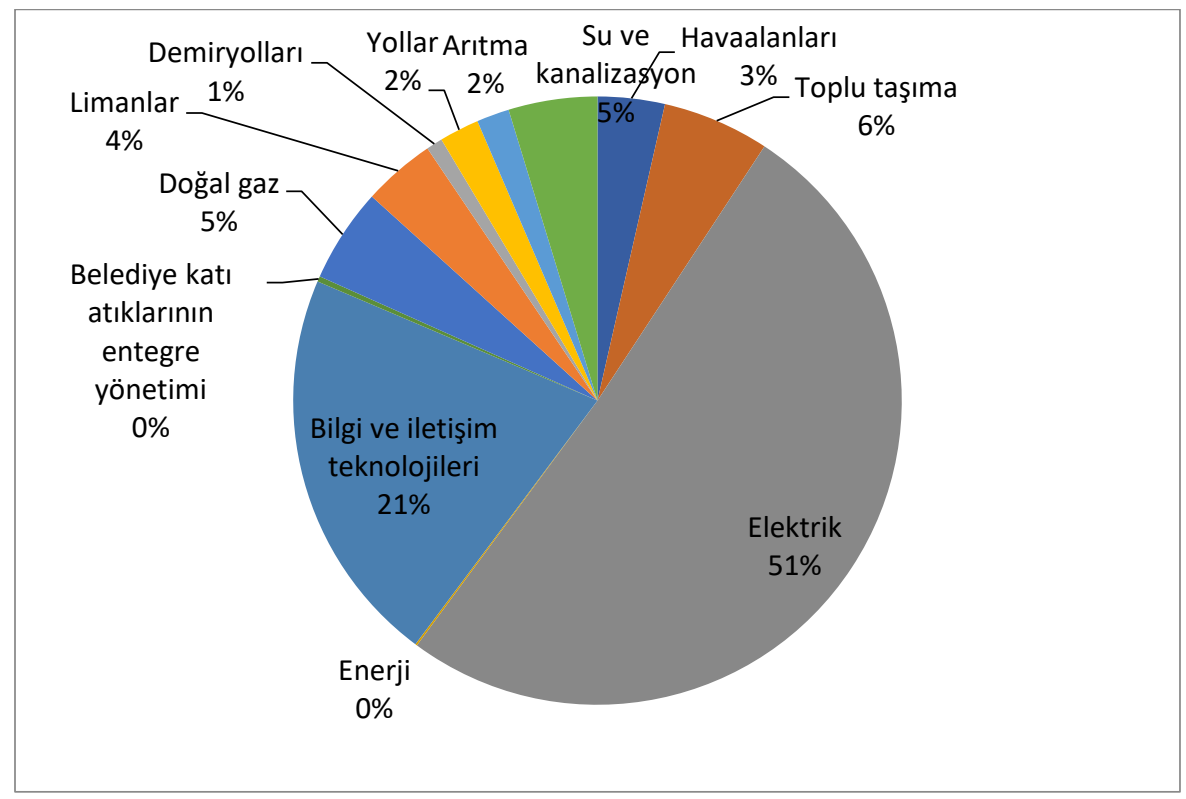

Grafik 3. Sektörlere Göre Finansal Kapanış Sağlayan Projeler(1990-2019)

Kaynak: The World Bank, 2019

1990-2019 yılı AB ve Orta Asya kamu özel ortaklığı pazarının sektörel dağılımı ele alındığında gerçekleştirilen proje sayısı bakımından elektrik sektöründeki projelerin \%51 oranla ilk sırada yer aldığı görülmektedir. Elektrik sektörü proje sayısını \%21'lik payla bilgi ve iletişim teknolojileri sektörü projeleri takip etmektedir. Toplu taşıma projelerinin oranı $\% 6$ gibi düşük bir orana sahiptir. Doğalgaz ve su kanalizasyon sektörlerinin projeleri \%5 oranina sahipken liman, havaalanı, yollar ve demiryolu proje oranları $\% 5$ 'in altında oranlara sahiptir.

\section{Türkiye'de Kamu Özel Ortaklığı Modeli}

Türkiye'de kamu özel ortaklığının somut örnekleri 1980 yılında görülmeye başlanmıştır. Eski Başbakanlar arasında yer alan Turgut Özal Yap-İşlet-Devret modelini literatüre kazandırmıştır. 1986 yılında ilk enerji santrali projesi ile bu model gerçekleştirilmiştir. Ardından İngiltere'de de bu model somut şekilde uygulamaya konulmuştur. Türkiye'yi ve bu modeli uygulayan diğer ülkelerin bu modeli tercih etme faktörleri ortaktır. Bu faktörler; 
- Hızlı nüfus artışı ve bunu tetikleyen altyapı ihtiyacındaki artış,

- Kentleşme nüfusundaki artış ile altyapı hizmletlerine olan talep artışı,

- Gelişmekte olan ülkelerin sebebiyet verdiği küresel krizlerin baş göstermesi,

- Küreselleşmenin etkisiyle büyük uluslararası şirketlerin yüksek kar beklentisi içine girerek uzun süreçli proje arayışlarına çımaları,

- Devletlerin finansman yaratmak için özelleştirmeye başvurmalarıdır (11.Kalkınma Planı-2019-2023).

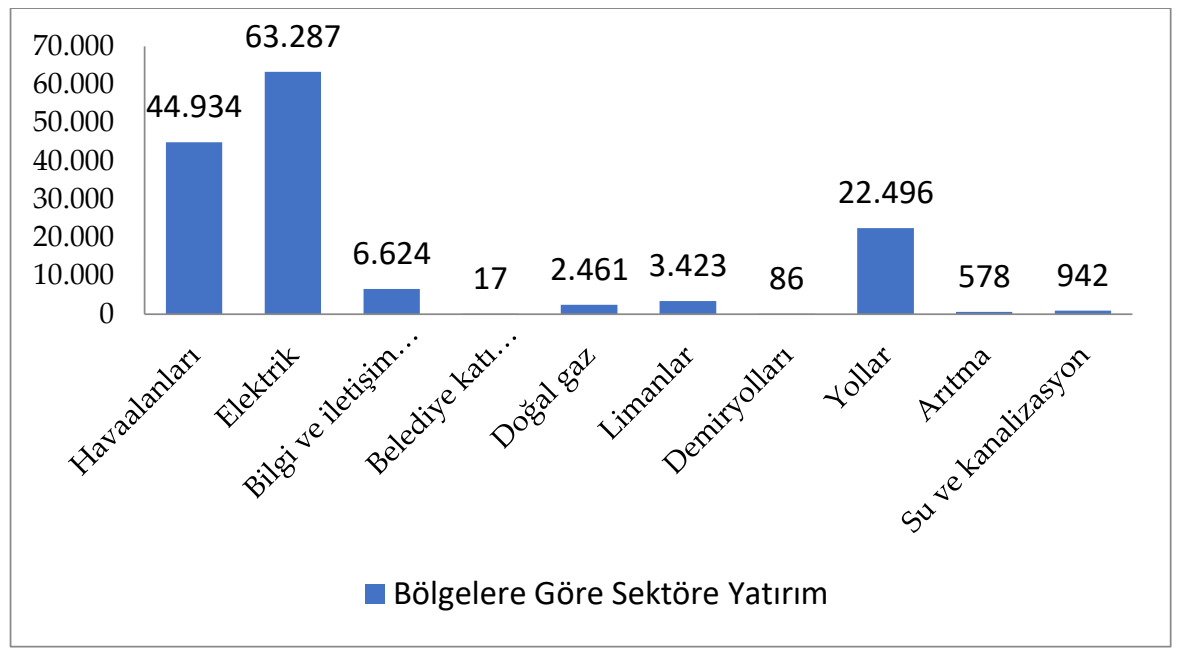

Grafik 4. Bölgelere Göre Sektörel Yatırm (Milyon Dolar) (1990-2019)

Kaynak: The World Bank, 2019

1990-2019 yılları arasında Türkiye'de sektörel proje yatırımları içerisinde elektrik sektörü proje yatırımları ilk içerisinde ilk sırada yer almaktadır. Havaalanları proje yatırımları 44.934 milyon dolar ile ikinci sırada yer almaktadır.Yol proje yatırımları da 22.496 milyon dolar ile ülkede öncelikli yatırım alanları arasında olduğunu göstermiştir. Bilgi ve iletişim teknolojileri projeleri 6.624 milyon dolar, doğalgaz projeleri 2.461 milyon dolar, liman projeleri 3.423 milyon dolar, demiryolları projeleri 86 milyon dolardır, arıtma projeleri 578 milyon dolar, su ve kanalizasyon projeleri de 942 milyon dolardır. En düşük yatırım tutarına sahip olan proje türü belediye katı atıklarının entegre yönetimi olmuştur. 


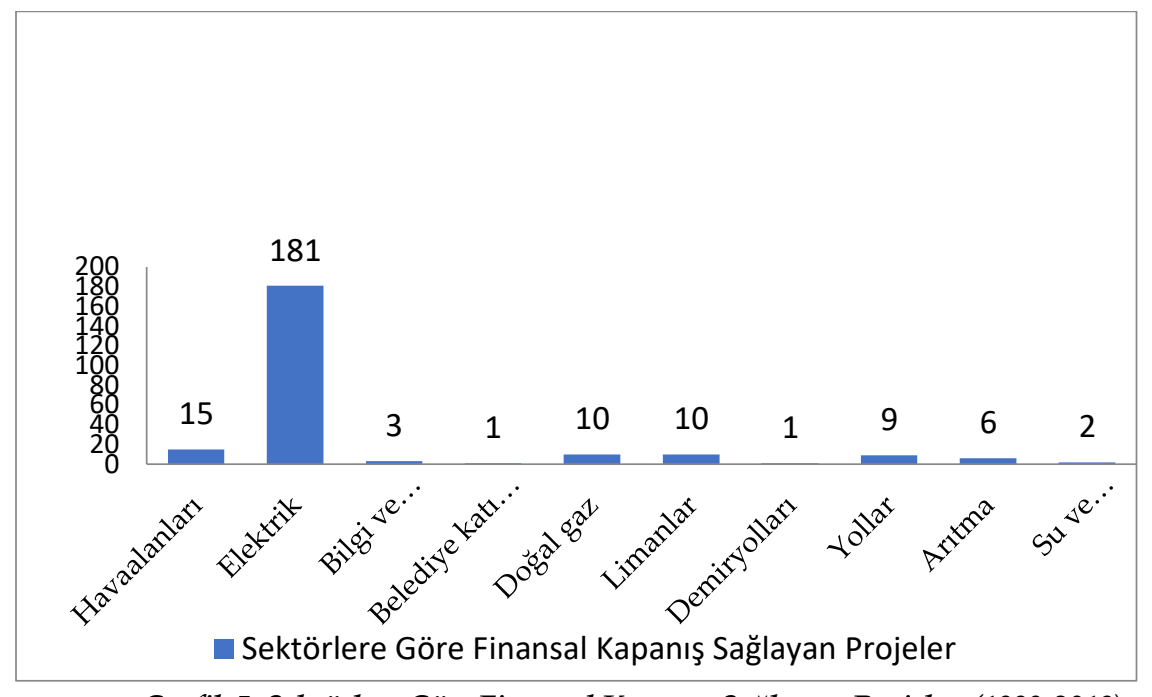

Grafik 5. Sektörlere Göre Finansal Kapanış Sağlayan Projeler (1990-2019)

Kaynak: The World Bank, 2019

Türkiye'de gerçekleştirilen proje sayıları itibariyle de elektrik sektörü projeleri ilk sırada yer almaktadır. 15 havaalanı projesini doğal gaz ve limanlar projeleri takip etmiştir. Su ve kanalizasyon projeleri ile belediye katı atıklarının entegre yönetimi proje sayıları da son sırada yer almaktadır.

\section{Tablo 2. Türkiye'de Kamu Özel Ortaklığı Proje Tutarlan}

\begin{tabular}{ll}
\hline Proje & Yatırum (milyon dolar) \\
\hline İstanbul Havaalanı & 35,587 \\
\hline Gebze-Orhangazi-Gebze Otoyolu & 9,756 \\
\hline Kemerköy ve Yeniköy Termik Santralleri & 7,576 \\
\hline Türk Telekom & 6,550 \\
\hline Üçüncü Boğaz Köprüsü ve Kuzey Marmara Karayolu Projesi & 2,900 \\
\hline Malkara Çanakkale Otoyolu & 2,842 \\
\hline Atatürk Havalimanı Kira Sözleşmesi & 2,543 \\
\hline Enerjisa I ve II Aşamaları & 2,539 \\
\hline Seyitömer Termik Santral & 2,248 \\
\hline Gebze Adapazari Izmir Elektrik Santralleri & 2,200 \\
\hline Kaynak: The World Bank, 2019
\end{tabular}

Dünya Bankası'nın raporlarına göre Türkiye'de kamu özel ortaklığı projeleri ile finansmanı sağlanan İstanbul Havaalanı projesinin yatırım tutarı 35.587 milyon dolardır. Bu yatırım tutarı ile diğer projeler arasında en yüksek 
tutara sahiptir. Gebze-Orhangazi-İzmir Otoyolu projesi 9.756 milyon dolarlık bir yatırım tutarına sahiptir. Termik santralleri proje yatırımları sırasıyla, Kemerköy ve Yeniköy Termik Santralleri projesi 7.576 milyon dolar, Enerjisa I ve II aşamaları projesi 2.539 milyon dolar, Seyitömer Termik Santrali projesi 2.248 milyon dolar ve Gebze Adapazarı İzmir Elektrik Santralleri projesi 2.200 milyon dolardir.

Tablo 3. Proje sayılarnın Yıllara Göre Dağılımı

\begin{tabular}{llll}
\hline YIL & SAYI & YIL & SAYI \\
\hline $\mathbf{2 0 1 9}$ & 4 & 2005 & 5 \\
\hline $\mathbf{2 0 1 8}$ & 8 & 2004 & 8 \\
\hline $\mathbf{2 0 1 7}$ & 11 & 2003 & 8 \\
\hline $\mathbf{2 0 1 6}$ & 14 & 2001 & 6 \\
\hline $\mathbf{2 0 1 5}$ & 5 & 2000 & 4 \\
\hline $\mathbf{2 0 1 3}$ & 14 & 1999 & 12 \\
\hline $\mathbf{2 0 1 2}$ & 35 & 1998 & 11 \\
\hline $\mathbf{2 0 1 1}$ & 8 & 1997 & 9 \\
\hline $\mathbf{2 0 1 0}$ & 14 & 1996 & 11 \\
\hline $\mathbf{2 0 0 9}$ & 15 & 1995 & 1 \\
\hline $\mathbf{2 0 0 8}$ & 4 & 1994 & 7 \\
\hline $\mathbf{2 0 0 7}$ & 8 & 1993 & 3 \\
\hline $\mathbf{2 0 0 6}$ & 9 & 1992 & 1 \\
\hline Kaynak & 1987 & 1 \\
\hline
\end{tabular}

Kaynak: TC. Cumhurbaşkanlığı Strateji ve Bütçe Başkanlı̆̆ı 2019

1987-2019 yılları arasında proje sayılarının yıllara göre dağılımı ele alındığında 2013 yılı 35 adet kamu özel ortaklığı projesiyle dikkat çekmektedir. 21.03.2013 tarihinde 6428 sayılı Sağlık Bakanlığınca Kamu Özel İş Birliği Modeli ile Tesis Yaptırılması, Yenilenmesi ve Hizmet Alınması İle Bazı Kanun ile Kanun Hükmünde Kararnamelerde Değişiklik Yapılması Hakkında Kanun düzenleme yapılmıştır. Bu kanun ile sağlık hizmetinde kamu özel ortaklığı modeli ile ilgili düzenlemeler gerçekleştirilmiştir.

1987-2019 yılları arasında toplam proje sayılarının modellere göre dağılımı ise işletme hakkı devri modelinden 111 proje gerçekleştirilmiştir. Yap işlet devret modelinden 110, yap kirala devret modelinden 20, yap işlet modelinden ise toplamda 5 proje gerçekleştirilmiştir. 
Tablo 4. Proje Sayılarının Sektörlere Göre Dağılımı

\begin{tabular}{ll}
\hline Sektör & Sayı \\
\hline Karayolu & 42 \\
\hline Havaalanı & 18 \\
\hline Yat Limanı ve Turizm Tesisi & 17 \\
\hline Demiryolu & 1 \\
\hline Kültür ve Turizm Tesisi & 1 \\
\hline Gümrük Tesisi & 19 \\
\hline Endüstriyel Tesis & 2 \\
\hline Sağlık Tesisi & 20 \\
\hline Enerji & 94 \\
\hline Liman & 23 \\
\hline Madencilik & 8 \\
\hline Katı Atı & 1 \\
\hline Kayn: & 23 \\
\hline
\end{tabular}

Kaynak: https://koi.sbb.gov.trl

\section{Ülkelere Göre Proje Değeri (milyar Euro) Ülkeye Göre Proje Sayısı}
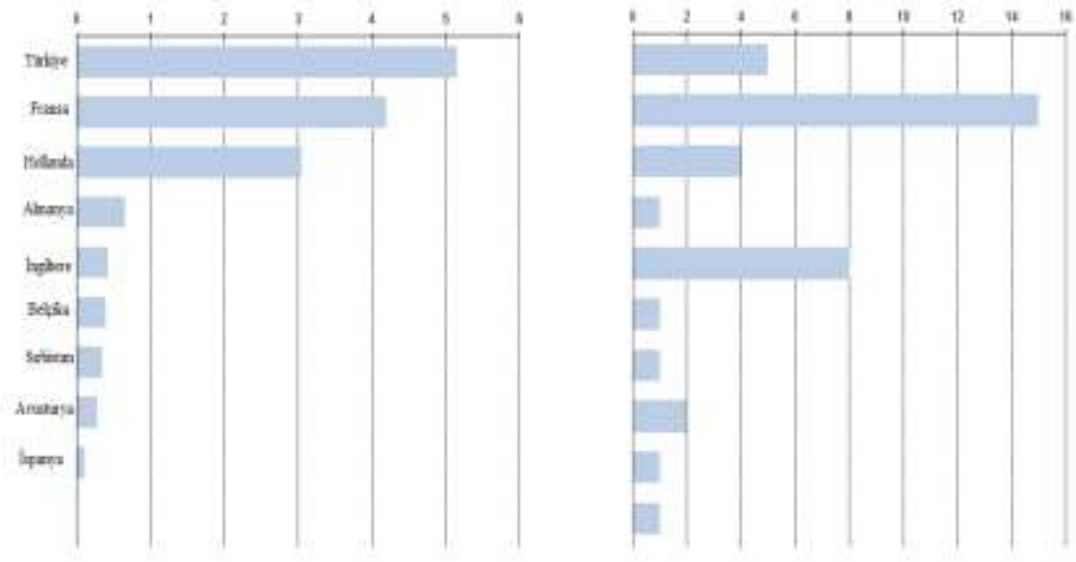

Grafik 6. 2018 Yılındaki Kamu-Özel Ortaklı̆̆ı Projelerinin Değerine ve Sayısına Göre Ülke Dağılımı, Kaynak:EPEC, 2018

Türkiye 2018 yılı raporlarına göre toplam 5.1 milyar Euro (2017'de 6 milyar Euro) ile değer bakımından Avrupa'nın en büyük Kamu özel ortaklığ1 pazarını oluşturmuş̧ur. 15 adet proje sayısı ile de Fransa öncü olmuştur. 
Fransa ayrıca toplam 4.2 milyar Euro ile ikinci büyük kamu özel ortaklığı pazarını oluşturmuştur. Son beş yılda İngiltere ve Fransa kapalı anlaşmaların sayısı bakımından kamu özel sektör ortaklık pazarını yönetirken Türkiye değer açısından en büyük kamu-özel ortaklık pazarı olmuştur (EPEC, 2018, s.2)

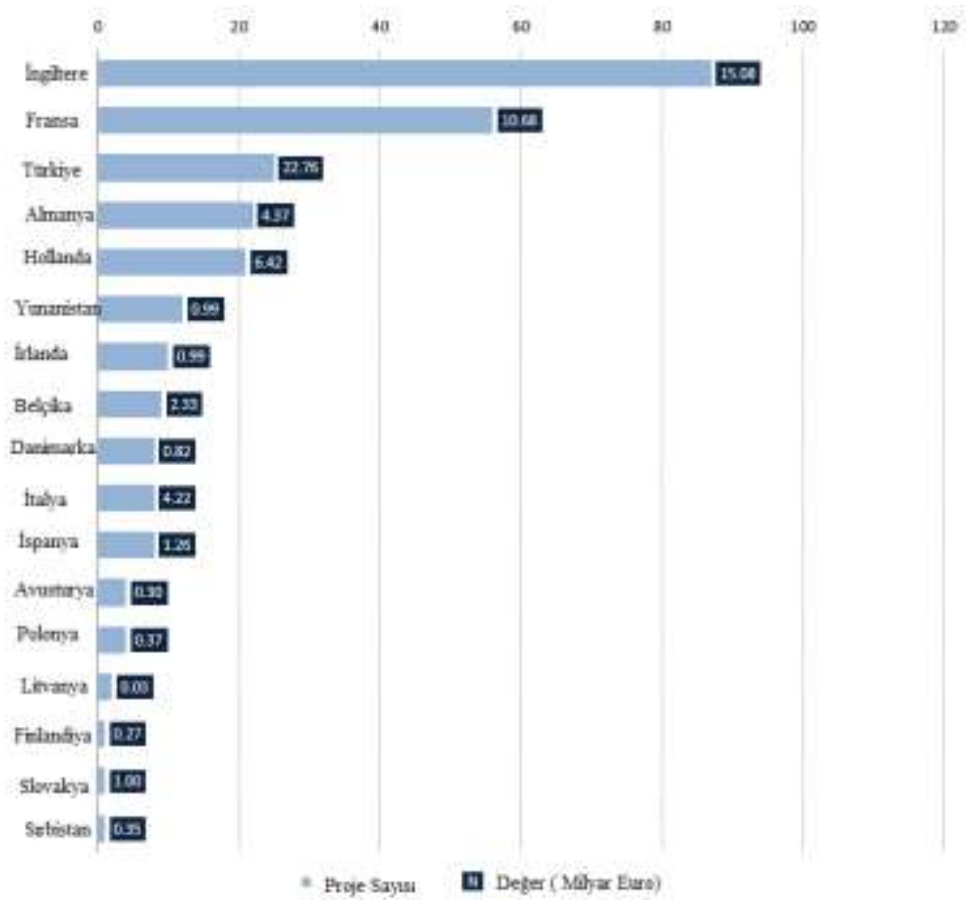

Grafik 7. Avrupa Kamu-Özel Ortaklı̆̆ı Pazarnın Ülkelere Göre Gelişimi (2014-2018) Kaynak:EPEC, 2018

2014-2018 yılları arasında Avrupa kamu özel ortaklığı pazarının ülkelere göre gelişiminde İngiltere proje sayısı bakımından pazarın lideri konumundadır. Proje maliyeti bakımından 15.08 milyar euro ile Türkiye'den sonra ikinci sırada yer almaktadır.

İngiltere' den sonra Fransa' da kamu özel ortaklığı pazarında 10.68 milyon euro ile önemli projelere adım atmıştır. Fransa için 2014-2018 yılları arası proje sayısı bakımından aktif bir dönem olmuştur. Türkiye, Almanya ve Hollanda bu yıllar arasında ortalama olarak benzer proje sayılarına sahip olsalar 
da Türkiye proje maliyeti bakımından tüm ülkelerin içinde en yüksek miktara sahip olmuştur.

Yunanistan, İrlanda, Belçika, Danimarka, İtalya ve İspanya'nın proje sayıları ortalama olarak İngiltere'nin proje sayısının beşte birine denk gelmektedir. Bu kamu özel ortaklığı pazarı içerisinde Avusturya, Polonya, Litvanya, Finlandiya, Slovakya ve Sırbistan gerek proje sayıları gerekse proje maliyeti bakımından minimum oranlara sahiptirler. Bu durumda bu ülkelerin 20142018 yılları arasında kamu özel ortaklığı modeline düşük oranlarda başvurduklarını göstermektedir.

\section{Sektörlere Göre Projelerin Toplam Değeri Sektörlere Göre Proje Sayısı (Milyar Euro)}
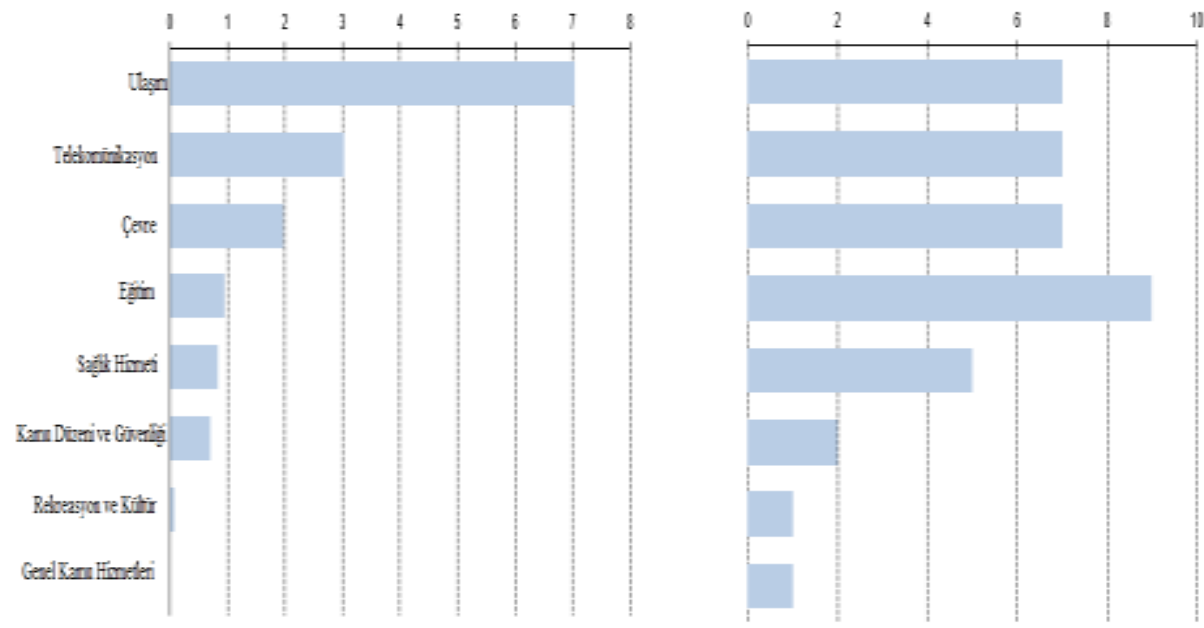

Grafik 8. 2018 Yılında Kamu-Özel Sektör İşbirliği Projelerinin Değerine ve Sayısına Göre Sektör Dă̆ılımı Kaynak:EPEC, 2018

2018 yılında taşımacılık sektörü 7 milyar Euro değerindeki işlemlerle (2017'de 7,6 milyar Euro) yatırım değeri açısından ilk sırada yer almaktadır. Bununla birlikte 2018, son 20 yılda sektörde kapatılan en az sayıda projeyi temsil etmektedir. Ulaşım sektörünün ardından telekomünikasyon sektörü 
toplam değeri 3 milyar Euro olan yatırım değeri ile en aktif ikinci sektör olmuştur. Bunun sebebi ağırlık olarak Fransa'da kapatılan altı geniş bant işleminden kaynaklanmaktadır.

Eğitim sektöründe finansal kapanışa ulaşan proje sayısı ondan dokuza düşmüş ve toplam değer de benzer şekilde 952 milyon Euro'ya gerilemiştir. 2017 yılında toplam değer 958 milyon Euro idi. Çevre sektöründe toplam 2 milyar Euro değerinde yedi proje kapatıldı. Sağlık sektörü hem değer (2017'de 3,8 milyar EUR'dan 2018'de 828 milyon Euro'ya) hem de proje sayıs1 açısından önemli ölçüde daralmıştır.

\section{İngiltere}

Türkiye örneğinde olduğu gibi, kamu özel ortaklı̆̆ı modelinin İngiltere'deki gelişimi de 1980'lerden sonra olmuştur. Bu dönemde siyasi hayat iki zit partinin iki temel görüşüne tanık olmuştur. Bu partiler sırasıyla Muhafazakar Parti ve İşçi Partisidir. 1980'lerin ve 1990'ların muhafazakar hükümetleri, özel sektörün kamu sektörü üzerinde önceliğe sahip olduğuna dair büyük bir inanca sahiptiler. Bu dönemde ilk olarak özelleştirme bir politika seçeneği olarak tercih edildi, ancak 1980'lerin sonunda özelleştirme olanakları sona erdi, hükümet özel sektörün katılımını teşvik etmek için alternatif yollar bulmak zorunda kaldı. (Kahyaoğulları, 2013, s.246). Böylece, kamu sektörünü özel sektör disiplinlerinin yardımıyla birleştirme girişimi, kamu sektörü kuruluşlarında özel sektör yönetimi yaklaşımlarının getirilmesi ve zorunlu rekabetçi ihalelerin genişletilmesi ile başlamıştır. 1992 yılında Özel Finans Girişimi (PFI) kurulduğunda, özel sektör politika oluşturma ve uygulamaya daha fazla dahil edilmiştir. Başlangiçta özel sektör esas olarak kamu hizmetlerinin sağlanmasına dahil edilirken, Özel Finans Gişimi'nin kurulmasıyla özel sektör, kamu sektörü tesislerinin tasarlanması, inşası ve işletilmesinde ana aktör haline gelmiştir.

İngiltere' de 1990'l y ylların başlarına kadar Özel Finans Girişimi, karayolu hizmetleri için yeni sözleşme fikirlerinin mükemmel bir şekli olarak yer almıştır. 1992 yılından itibaren Özel Finans Girişimi özel sektörü devlet projelerine katılmaya teşvik etmek amacıyla kullanılmaya başlanmıştır. 1992 yılı sonunda İngiliz Ulaştırma Bakanlığı bu sistemle yolların tasarlanması, inşa edilmesi, finanse edilmesi ve işletilmesi gerektiğini açıklamıştır. Tasarım, inşaat, finansman ve işletme sözleşmelerinin bu konudaki fikirlerinin çoğu, 
Mayıs 1993'te yayımlanan 'Daha İyi Otoyollar İçin Ödeme' başlıklı bir politika belgesinde belirtilmiştir. Yol hizmetini özel ortaklarla inşa etme ve işletme yükümlülüklerini üstlenmenin iki temel faydasının olduğu belirtilmiştir. Birincisi, özel ortakların projenin her aşamasında riskleri absorbe edebilmesiydi. Sözleşme uzun bir süre devam edeceğinden, özel aktörler yollar inşa etmek ve işletmek için yeni yollar deneyebilirler. Özel Finans Girişimi'nin ikinci amacl, Ulaştırma Bakanlığı'na göre o dönemde neredeyse hiç bulunmayan bir özel sektör yol bakım endüstrisini tanıtmaktı. (Klijn ve Teisman, 2005, s.99-100).

İngiltere' de kamu özel ortaklığı modelini savunanların yanında tamamen bu modele olumsuz bakanlar da bulunmaktadır. Kamu özel sektör işbirliği projelerinin birtakım risk ve sorunlar taşıdığı ileri sürülmektedir. Kamu özel sektör işbirliği projelerinin, hükümete, kamu altyapısını borçlanarak finanse etmekten daha pahaliya mal olduğunu ifade etmektedirler. İşbirliği içine girilen özel şirketlerin, bu ortaklıklardan büyük kazanımlar elde ettikleri iddia edilmektedir. Ayrıca bu şirketlerin vergiden kaçınma imkanlarından yoğun biçimde faydalanmaları sebebiyle hükümet açısından mali bir kayıp oluştuğunun da altı çizilmektedir. Bu model, sunulan hizmet standartlarının ve personel standartlarının düşmesine yol açmıştır. Ayrıca bu modelin demokratik hesap verilebilirliği de aşındırdığı ifade edilmektedir (Jubile Debt Campaign, 2017, s.2).

Kamu özel ortaklığı modeli İngiltere'de sanılanın aksine popüler bir hal almamıştır. Yapılan bir anket çalışmasında ankete katılanların \%68'i kamu özel ortaklığı modelinin yasaklanmasını talep etmişlerdir. Kişi başına daha fazla projeye sahip olan İskoçya'da ise, katılımcıların \% 76'sı bu modelin yasaklanması gerektiğini ifade etmiştir (Jubile Debt Campaign, 2017, s.2). İngiltere dışında Avrupa Birliği ülkelerinde kamu özel ortaklığı projelerini başarıyla uygulayan başka ülkeler de bulunmaktadır. Örneğin, Fransa yüz yıldan fazla bir süredir kamu özel ortaklığı politikasını oldukça iddialı bir şekilde uygulayan ülkelerden biridir. Ayrıca Fransa'da en çok benimsenen kamu özel ortaklığı modeli, Türkiye'deki sisteme benzeyen imtiyaz sistemidir. Türkiye'nin çeşitli politika belgelerinde İngiltere'deki kamu özel ortaklı̆̆ı modeli politikasının rol model olarak alındığı vurgulanmıştır. Türkiye'deki Uluslararası Kamu Özel Ortaklığı Modeli Platformu, İngiltere'nin en başarılı poli- 
tika uygulayıcılarından biri olduğunu ve dolayısıyla İngiltere'nin yolunu takip edeceğini vizyonlarında açıça belirtmektedir (Kahyaoğulları, 2013, s.246).

\section{Sonuç}

Kamu özel ortaklı̆̆ için üzerinde uzlaşıya varılmış tek bir tanım olmasa bile, bu modelin çeşitli ülke uygulamalarında ortaklaşa görülen birçok özelliği olduğu da bir gerçektir. Bu ortak özellikler öncelikle risk faktörü, ortaklar, maliyetler, faydalar, kaynaklar ve sorumluluklardır. Kamu özel ortaklığı modelinin özellikle özelleştirme ile karıştırılmamasının da altı çizilmiştir.

Kamu özel ortaklığı modelinin avantajları ve dezavantajları ele alınmıştır. $\mathrm{Bu}$ modelin en fazla önem atfedilen özelliklerinden birisi olan risk faktörünün özel sektör ile paylaşımı önemli avantajlar arasında yer almaktadır. Geleneksel yöntemler ile mukayese edildiğinde yüksek maliyet, karar vermede esnekliğin düşük olması ve birtakım şeffaflık sorunlarını ortaya çıarması önemli dezavantajlar arasında yer almaktadır.

Bu çalışmada kamu özel ortaklığı modelinde dünyada lider olarak yer alan İngiltere ele alınmıştır. İngiltere'de, risk paylaşımı faktörü sebebiyle bu modeli savunanlar olduğu gibi; modelin uygulanmasının aşırı maliyete sebep olması, hizmet standartlarını düşürmesi gibi sebeplerden dolayı karşı olanlar da bulunmaktadır.

Avrupa ve Orta Asya'da kamu özel ortaklığı modelinde bölgelere göre sektörel yatırımlar içerisinde eletrik yatırım projelerinin 131.853 milyon dolar ile ilk sırada yer aldığı çalışmamızda görülmüştür. Elektrik üretimi projelerini 51.183 milyon dolar ile havaalanları yatırım projeleri izlemektedir. Enerji yatırım projeleri ise 6 milyon dolar ile son sırada yer almaktadır. Bu yatırım projelerini oluşturan ülkeler arasında ise Türkiye, Rusya Federasyonu ve Belarus yer almaktadir.

1990-2019 yılları verilerine göre Türkiye sektörel yatırım projeleri içerisinde elektrik yatırım projeleri 63.287 milyon dolar ile ilk sırada yer almaktadır. Havaalanları yatırım projeleri 44.934 milyon dolar ile ikinci sırada yer almaktadır. Belediyelerin katı atıklarının entegre yönetimleri yatırım projeleri 17 milyon dolar ile son sırada yer almaktadır. 2018 yılında Türkiye, kamu 
özel ortaklığında proje maliyeti açısından ilk sırada yer almaktadır. Türkiye'yi Fransa, Hollanda, Almanya ve İngiltere takip etmektedir. Yatırım proje sayıları bakımından ise Fransa ilk sırada yer almaktadır.

Dolayısıyla Türkiye'nin gelişmekte olan ülkeler arasında kamu özel ortaklığı projelerini uygulama ve benimseme konusunda iyi örnekler arasında yer aldığ görülmektedir. Günümüze kadar çeşitli kamu özel ortaklığ projelerinde yap-iş-devret, yap-işlet, yap-kirala, imtiyaz, işletme hakkı gibi yöntemlere başvurulmuştur. Geçmişten günümüze kadar kamu hizmetlerinde artan çeşitlilik ve vatandaşların çeşitlilik beklentisi ile birlikte devletin kaynaklarının sınırlılığ anlayışının da önemle üzerinde durduğu kamu kaynaklarının verimli ve etkin kullanımı anlayışı doğrultusunda, daha kaliteli hizmet sunma avantajı sağlayan kamu özel ortaklığı modeli uygulamalarına sıklıkla başvurulmaktadır. Bu yöntem bu zamana kadar başvurulan yatırım programlarının bir tamamlayıcısı olarak yer almaktadır ve almalıdır. 


\title{
EXTENDED ABSTRACT
}

\section{Public-Private Partnership in Turkey within the Context of Europe and Central Asia}

\author{
Semra Altıngöz Zarplı \\ Bilecik Şeyh Edebali University
}

There are different definitions for the partnership model of public and private sector defining the voluntary union of private and public sector as a partnership. Public-private partnership may be defined as regulations where the private sector joins or supports the infrastructure procurement. In other words, it allows the agreement of a private institution aiming at providing services based upon public infrastructure.

It is seen that an agreement has not been reached in the definition of public-private partnership. However, it is addressed in two big categories. The first category defines public-private partnership in a broad sense. Public interference, public and infrastructure services covering a wide range of publicprivate collaboration forms is defined as public-private partnership. According to the second category, it is considered necessary to bring some characteristics together in order to be able to discuss public-private partnership. These characteristics are risks, partners, sharing between public and private partners, costs, benefits, resources and responsibilities. We believe that the second category is closer to what public-private partnership means. However, public-private partnership appears in various forms due to various fields, the properties of states and the different needs in international practices. It is seen that some expressions regarding public-private partnership model are misinterpreted based on all these definitions. The public-private partnership model should not be interpreted as a privatization. It is a process where private sector takes an operational role through a long-term prerogative or financial leasing agreement in a public project. Unlike privatization, this partnership is the transfer of the ownership or title of a public utility to a private enterprise.

In this study, it is seen that a consensus has not been fully reached for the definition of public-private partnership in the world, but that there are many properties coming to the forefront in the public-private partnership model. These common characteristics are primarily risk factor, partners, 
costs, benefits, resources and responsibilities. It is also highlighted that public-private partnership model should not be interpreted as privatization. The advantages and disadvantages of the public-private partnership were discussed. The sharing of the risk factor with the private sector, one of the most significant characteristic of this model, is among the important advantages. The model's high cost, low level of flexibility in decision making and revealing some transparency problems are among the disadvantages when compared with traditional methods.

In the public-private partnership model, the UK acting as the leader in the world and it was found that the number of those who were against this model due to its excessive cost and the fact that its lowering service standards was quite high compared to those defending because of the risk sharing factor. Electricity investment projects take the first place with 131.853 million dollars among sectoral investments according to regions in the public-private partnership model in Europe and Central Asia. Airport investment projects rank the second with 51.183 million dollars following the electricity generation projects. Energy investment projects take the last place with 6 million dollars. Turkey, Russian Federation and Belarus are among the countries making these investment projects.

According to the data between 1990-2019, Turkey ranked the first with 63.287 million dollars with its electricity investment projects among sectoral investment projects. Airports investment projects took the

second place with 44.934 million dollars. The integrated waste management projects of municipalities regarding solid wastes took the last place with 17 million dollars. Turkey ranked the first in terms of project cost in publicprivate partnership in 2018. Turkey was followed by France, the Netherland, Germany and the UK. France took the lead in terms of the number of investment projects.

Therefore, it has been presented that Turkey is among the good examples regarding the practice and adoption of public-private partnership projects among developing countries. Methods such as build-operate-transfer, buildoperate, build-rent, prerogative and right to operate have been adopted in various public-private partnership projects up until today. Increasing diversity in public services, the expectations of citizens and the limited resources of the state have led to different pursuits from past to present. In line with the understanding of productive and efficient use of public resources where the 
new understanding of public financial management is also important, the public-private partnership model practices providing the advantages of offering more qualified service have been frequently applied. This method serves and should serve as a complementary part of the previously applied investment programs.

\section{Kaynakça / References}

European PPP Expertise Centre (2018). Market update review of the European PPP Market in 2018.

Grimsey, D. ve Lewis, M.K (2014). Public private partnerships, the worldwide revolution in infrastructure provision and project finance. UK: Edward Elgar Yayınları.

Jubile Debt Campaign. (February 2017). The UK's PPPs Disaster, Lessons on private finance for the rest of the world.

Kahyaogullari, B. (2013). Public-Private partnerships in developing and developed countries: the UK and Turkish cases. Afyon Kocatepe Üniversitesi, IIBF Dergisi.

Klijn, E. H., ve Teisman, G. (2005). Public-private partnerships as the management of co-production: strategic and institutional obstacles in a difficult marriage. The challenge of public-private partnerships: Learning from international experience, 95-116.

Levy, S. M. (2011, September). Public-private partnerships: Case studies on infrastructure development. American Society of Civil Engineers.

Martin, L. L. (2018). Public-private partnerships (P3s): What local government managers need to know. Washington, DC: International City/County Management Association (ICMA). Retrieved January, 10, 18-109.

Türkiye Cumhuriyeti Cumhurbaşkanlığı Strateji ve Bütçe Başkanlığı (t.y). Kamuözel işbirliği ile yürütülen projeler. https://koi.sbb.gov.tr/ adresinden erişilmiştir.

Taylor, M. (2012). Maximizing state benefits from public private partnerships. State of California Legislative Analysts Office. 16. 
T.C. Kalkınma Bakanlığı, Kalkınma Planı [2019-2023] (2018)., Kamu özel işbirliği uygulamalarında etkin yönetim özel ihtisas komisyonu raporu, Ankara http://www.sbb.gov.tr/wp-content/uploads/2020/04/KamuOzelIsbirligiUygulamalarindaEtkinYonetimOzellhtisasKomisyonuRaporu.pdf adresinden erişilmiştir.

The World Bank Infrastructure Finance, PPPs \& Guarantees.(2019). 07.03.2020 tarihinde https://ppi.worldbank.org/. adresinden erişildi.

Türkiye Cumhuriyeti Cumhurbaşkanlığı Strateji ve Bütçe Başkanlığı. (2019). Kamu özel işbirliği ile yürütülen projeler. 04.03.2020 tarihinde https://koi.sbb.gov.tr/ adresinden erişildi.

Zaharioaie, M. (2012). The utility of using public private partnership for local governments. Journal of Public Administration, Finance and Law, 2, 17-24.

\section{Kaynakça Bilgisi / Citation Information}

Zarplı Altıngöz, S. (2020). Avrupa ve Orta Asya bağlamında Türkiye'de kamu özel ortaklığı. OPUS-Uluslararası Toplum Araştırmaları Dergisi, 15(26), 4623-4643. DOI: 10.26466/opus.734382 